\title{
PLANEJAMENTO ENERGÉTICO RURAL ASSISTIDO POR COMPUTADOR ${ }^{1}$
}

\author{
MANUEL R. BORGES NETO ${ }^{2}$, PAULO C. M. DE CARVALHO
}

RESUMO: Este trabalho traz o desenvolvimento de ferramenta computacional de auxílio ao planejamento energético na eletrificação rural, tendo como referência os principais softwares disponíveis no mercado mundial e citados na literatura científica. Após identificar as principais limitações dos mesmos, obteve-se um produto em português, que compara a extensão da rede convencional de energia elétrica às principais modalidades de geração elétrica de pequeno porte em uso no Brasil. Traz a inovação do dimensionamento e do uso da geração de energia elétrica a partir da produção de biogás no local. Para validação do programa, foram comparados os resultados obtidos pela mesma em dois estudos de casos reais de eletrificação rural.

PALAVRAS-CHAVE: energia, fontes renováveis, geração descentralizada.

\section{COMPUTER AIDED RURAL ENERGY PLANNING}

ABSTRACT: This paper brings the development of a computational tool to help the energy planning in rural electrification areas by using the main software available on the world market or cited in scientific literature, as in the reference. After identifying its main limitations, a product in Portuguese was obtained, which compares the extension of conventional electric grid to the main small size renewable energy sources under use in Brazil. It also brings the innovation in the dimensioning and in the use of electric energy generation by the local biogas production. For the program validation, the results obtained by the tool were compared in two real study cases of rural electrification.

KEYWORDS: energy, renewable sources, decentralized generation.

\section{INTRODUÇÃO}

A disponibilidade de energia elétrica no meio rural é um importante vetor de desenvolvimento. A partir desse recurso, é possível favorecer a irrigação, automatizar processos, beneficiar produtos e permitir, em alguns casos, atividades produtivas no período noturno. Ocorre que, no Brasil, justamente esse setor apresenta restrições no tocante ao fornecimento de eletricidade.

O modelo adotado para o setor elétrico brasileiro contribuiu para o êxodo rural, quando essa população passou a ocupar os centros urbanos, levando consigo não só a demanda por energia elétrica, mas também todas as demais associadas a uma comunidade, tais como: educação, moradia, saúde e saneamento (CARVALHO \& CRAVEIRO, 2006).

Nas últimas décadas, a privatização de parte do setor elétrico brasileiro acentuou a exclusão à energia elétrica, pois a eletrificação para o meio rural geralmente tem esbarrado em aspectos financeiros, como a baixa densidade da carga, ocasionada pela dispersão das instalações, colaborando para o afastamento do investidor privado (WEITZEL et al., 2006).

Logo, resta a entidades governamentais arcar com tais despesas que, ao disponibilizar tal infraestrutura, assume papel social não só absorvendo o ônus dos investimentos iniciais, mas também concedendo subsídios às tarifas cobradas. Ocorre que tais recursos, via de regra, são mantidos por meio de arrecadação tributária e, ainda que indiretamente, são repassados aos demais contribuintes (NASCIMENTO et al., 2003; NASCIMENTO et al., 2005).

\footnotetext{
${ }^{1}$ Extraído da Dissertação de mestrado do primeiro autor

${ }^{2}$ Prof., Mestre do Instituto Federal de Educação, Ciência e Tecnologia do Sertão Pernambucano, Petrolina - PE, rangel@cefetpe.br

${ }^{3}$ Prof. Doutor, Universidade Federal do Ceará, PPGEE-DEE-UFC, carvalho@ dee.ufc.br

Recebido pelo Conselho Editorial em: 30-10-2007

Aprovado pelo Conselho Editorial em: 17-6-2009
} 
É comum, ao se planejar a eletrificação de uma propriedade no meio rural, verificar somente a opção da extensão da rede elétrica, sem, contudo, levar em consideração a possibilidade de geração de energia no próprio local. Essa última, caracterizada como Geração Descentralizada (GD), além de possibilitar o desenvolvimento por meio da energia elétrica gerada, pode agregar outros benefícios importantes para o local, como: a utilização dos recursos naturais, a geração de mão de obra tanto na construção como na manutenção e o uso de tecnologias ou fontes de energias renováveis (DIAS et al., 2006).

Porém, projetos dessa natureza envolvem diversas variáveis de estudo. Para auxiliar esse tipo de análise, o uso de softwares de dimensionamento e de planejamento surge como importante opção para uma avaliação mais ágil e coerente com a realidade local.

Propõe-se, neste artigo, a apresentação de um programa computacional de auxílio à tomada de decisão no planejamento energético do meio rural.

\section{MATERIAL E MÉTODOS}

Como primeiro passo, buscou-se localizar, no mercado mundial e na literatura científica, programas de auxílio no planejamento de eletrificação no meio rural que utilizassem energias renováveis e a rede elétrica convencional (QUASCHINING \& ZEHNER, 2004; NOGUEIRA \& ZÜRN, 2005; MARINI \& ROSSI, 2005).

Verificou-se a existência no mercado de diversos programas computacionais com esse propósito, tais como: INSEL $®$; PV-DESIGN PRO®, GREENIUS®; HOMER $®$ e o RETScreen ${ }^{\circledR}$. À exceção dos dois últimos, distribuídos gratuitamente, os demais têm o custo da licença de uso variando de 50 a 1.200 Euros. A maioria dos programas foi desenvolvida em países industrializados do Hemisfério Norte e apresentam como características comuns:

a) $\mathrm{O}$ uso da língua inglesa, além do idioma de origem. Embora a língua inglesa seja considerada idioma mundial, para a realidade de líderes comunitários, técnicos e engenheiros no meio rural brasileiro, a leitura de textos nesse idioma pode ainda significar uma barreira.

b) Normalmente aplicam-se a sistemas conectados à rede elétrica convencional, com parâmetros adotados um tanto diferentes dos que seriam para GD.

c) Em geral, são dedicados ao projeto de grandes instalações (centenas de kW ou mesmo MW), o que dificulta a aplicação em sistemas autônomos em pequenas instalações rurais.

d) O estudo da biomassa, quando disponível, é voltado somente para fins de aquecimento e de conforto térmico. Não há aplicações para a geração de energia elétrica.

e) As análises financeiras realizadas dificultam a aplicação em países em desenvolvimento, uma vez que utilizam valores de produtos e serviços adotados em países industrializados.

Em virtude de tais características, foi gerada a motivação para o desenvolvimento, pelos autores, no âmbito do Programa de Pós-Graduação em Engenharia Elétrica, da Universidade Federal do Ceará, de programa computacional mais bem adaptado à realidade brasileira. Dessa forma, busca-se atender à demanda social intrínseca, onerando o mínimo possível o erário, sem, contudo, deixar de garantir energia de qualidade, continuidade nos serviços e baixo impacto socioambiental.

Desenvolvida em planilha Excel®, o programa GDER tem as funcionalidades apresentadas por meio do quadro-resumo da Figura 1. 


\begin{tabular}{|c|c|c|c|}
\hline Passo & Tela & Dados de entrada & Dados de saída \\
\hline 1 & Abertura & Iniciar & Não há \\
\hline 2 & Demanda elétrica & $\begin{array}{c}\text { Taxa de crescimento; } \\
\text { Fator diversidade; } \\
\text { Horas de funcionamento diário; } \\
\text { Potência instalada por unidade, e } \\
\text { Quantidade de unidades consumidoras. }\end{array}$ & Demanda elétrica estimada \\
\hline \multirow[t]{2}{*}{3} & $\begin{array}{l}\text { Conjunto motor- } \\
\text {-gerador a } \\
\text { biogás }\end{array}$ & \multirow[t]{2}{*}{$\begin{array}{l}\text { Disponibilidade de matéria orgânica; } \\
\text { Profundidade admissível do solo, e } \\
\text { Pressão de gás desejada. }\end{array}$} & $\begin{array}{c}\text { Potência do conjunto motor-gerador a gás; } \\
\text { Consumo em } \mathrm{m}^{3} \mathrm{~h}^{-1} \text {; Custo estimado; Biodigestor } \\
\text { sugerido (medidas de gasômetro, profundidade e } \\
\text { quantidade); Custo estimado do arranjo; Análise } \\
\text { da biomassa disponível, e Opções de acréscimo } \\
\text { da biomassa. }\end{array}$ \\
\hline & $\begin{array}{l}\text { Conjunto motor- } \\
\text {-gerador a } \\
\text { diesel }\end{array}$ & & $\begin{array}{c}\text { Potência do conjunto gerador-motor diesel; } \\
\text { Consumo em } \mathrm{L} \mathrm{h}^{-1}, \mathrm{e} \\
\text { Custo estimado do gerador diesel } \\
\end{array}$ \\
\hline 4 & $\begin{array}{l}\text { Solar fotovoltaico } \\
\qquad(\mathrm{FV})\end{array}$ & $\begin{array}{l}\text { Dias de armazenamento da carga; } \\
\text { Eficiência de conversão cc-ca; } \\
\text { Tensão nominal do sistema; } \\
\text { Horas de sol pleno; } \\
\text { Latitude do local; } \\
\text { Fator de eficiência das baterias; } \\
\text { Profundidade de descarga máxima; } \\
\text { Capacidade nominal das baterias; } \\
\text { Tensão nominal da bateria; } \\
\text { Fator de correção do módulo FV; } \\
\text { Corrente nominal do módulo, e } \\
\text { Tensão do módulo para temperatura } \\
\text { mais alta. }\end{array}$ & $\begin{array}{c}\text { Potência total do arranjo; } \\
\text { Distribuição em série e/ou paralelo dos módulos } \\
\text { FV e baterias; } \\
\text { Quantidade e potência do inversor de frequência; } \\
\text { Quantidade e potência do controlador de carga, e } \\
\text { Custo individual e total dos arranjos FV. }\end{array}$ \\
\hline 5 & Energia eólica & $\begin{array}{l}\text { Para a série histórica de um ponto de } \\
\text { medição; } \\
\text { Dois pontos de medição, e } \\
\text { Dados já processados. }\end{array}$ & $\begin{array}{c}\text { Potência e quantidade dos aerogeradores; } \\
\text { Quantidade de baterias em série e/ou paralela; } \\
\text { Quantidade e potência dos controladores de } \\
\text { carga; Quantidade e potência dos inversores de } \\
\text { frequência, e Custo individual e total dos arranjos } \\
\text { eólicos. } \\
\end{array}$ \\
\hline 6 & Análise financeira & $\begin{array}{c}\text { Taxa de retorno; } \\
\text { Preço do kWh para o local; } \\
\text { Valor médio por km de rede elétrica; } \\
\text { Distância da rede elétrica; } \\
\text { SM vigente; } \\
\text { Período de manutenção, estimativa de } \\
\text { despesas com manutenção: rede elétrica, } \\
\text { motor-gerador a gás, motor-gerador a } \\
\text { diesel, biodigestores, baterias, geradores } \\
\text { eólicos, painéis FV; } \\
\text { Preço estimado do m de biofertilizante, } \\
\text { e } \\
\text { Vida útil das baterias. }\end{array}$ & $\begin{array}{l}\text { Para cada modalidade de fornecimento, são } \\
\text { apresentados os parâmetros: relação benefício- } \\
\text {-custo }(\mathrm{B} / \mathrm{C}) \text {; o preço estimado do kWh } \\
\left(\mathrm{R} \$ \mathrm{kWh}^{-1}\right) \text { e o valor de recuperação de capital. }\end{array}$ \\
\hline 7 & Gráficos & $\begin{array}{l}\text { Utiliza os dados de saída do passo } \\
\text { anterior. }\end{array}$ & $\begin{array}{l}\text { Gráfico comparativo do valor do custo do kWh e } \\
\text { relação benefício-custo; } \\
\text { Gráfico comparativo do custo de instalação } \\
\text { inicial, e Valor do custo anual de recuperação de } \\
\text { capital. }\end{array}$ \\
\hline
\end{tabular}

FIGURA 1. Resumo das funcionalidades do programa GDER. GDER program functionalities abstract.

Como mostrado, após a abertura do aplicativo, o usuário é conduzido pelas telas interativas que serão explicadas passo a passo. Em seguida, o programa é validado pela aplicação em dois estudos de casos de eletrificação rural. 


\section{Passo 1 - Tela de abertura}

Ao se iniciar o GDER, é apresentada ao usuário a tela de abertura do programa, conforme a Figura 2. Ativando-se o botão Iniciar, o programa conduz o usuário para a planilha seguinte, ou Passo 2.

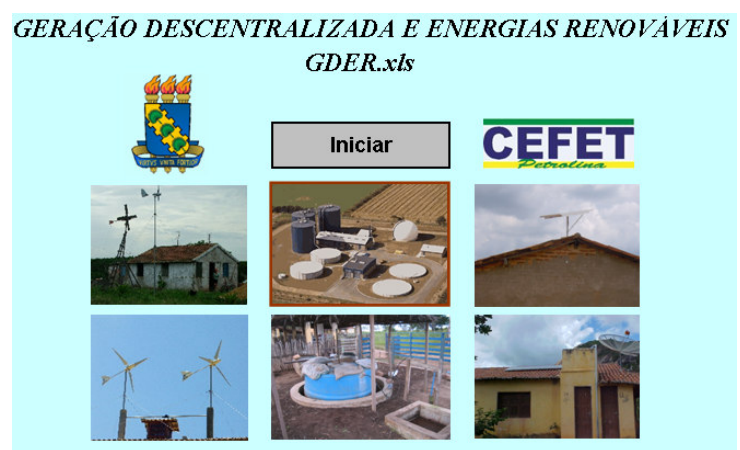

FIGURA 2. Tela principal do programa computacional desenvolvido. Main screen of the developed computational program.

\section{Passo 2 - Demanda elétrica}

Nessa etapa, o usuário deve informar os dados referentes à potência e ao funcionamento da carga a ser eletrificada. A planilha, por sua vez, calcula parâmetros como a demanda elétrica e o consumo de energia elétrica da carga.

\section{Passo 3 - Conjunto motor-gerador a biogás e a diesel}

Nesse bloco, a planilha dimensiona o grupo motor-gerador suficiente para atender à demanda da instalação utilizando duas opções de combustível: o biogás, que pode ser produzido na própria localidade, ou o óleo diesel.

\section{a) Biogás}

Deve ser informada pelo usuário a quantidade de animais existentes, ou outras matérias orgânicas disponíveis na localidade, a partir da interação com os campos encontrados na parte superior esquerda da tela (Figura 3).

O modelo de biodigestor adotado pelo programa é o Indiano, tanto por sua difusão no Brasil como pela facilidade no controle da pressão de saída do gás produzido. Por ser construído enterrado no solo, a informação profundidade do solo é requerida pela planilha; outra informação também solicitada ao usuário é a pressão do gás desejada.

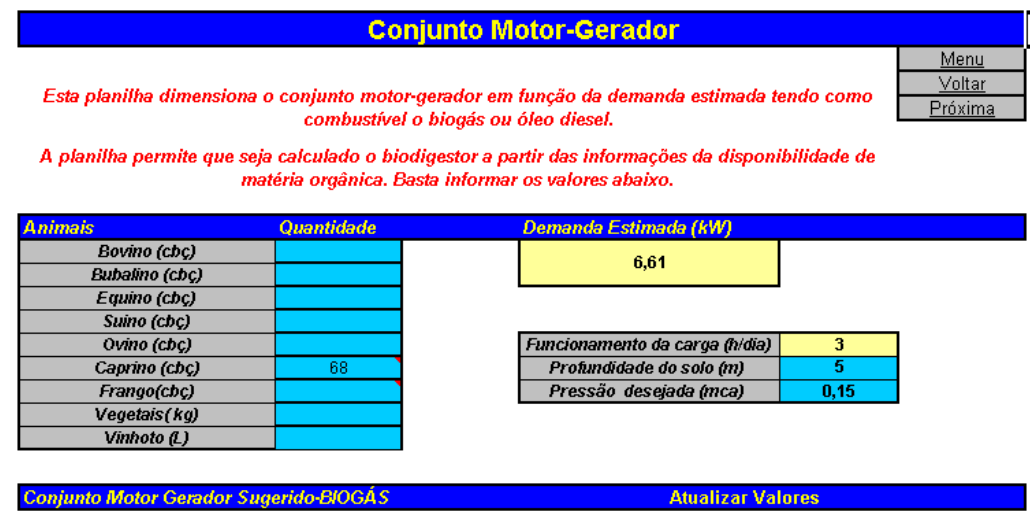

FIGURA 3. Tela para o dimensionamento do conjunto motor-gerador/entrada de dados. Screen for generator set/data entry designing.

Ao utilizar o conjunto motor-gerador, é recomendável que o mesmo não trabalhe com carga muito baixa, sendo usual adotar que a potência elétrica da carga não seja inferior a $40 \%$ da potência 
nominal do conjunto motor-gerador. Esse parâmetro, denominado de carregamento, é calculado pela divisão do valor da demanda estimada e da potência nominal do conjunto motor-gerador.

O programa busca, dessa forma, em sua biblioteca, o conjunto motor-gerador que melhor atenda à demanda estimada; em seguida, retorna os resultados conforme apresentado na Figura 4, que mostra o resultado do dimensionamento do biodigestor para o acionamento do conjunto motor-gerador selecionado.

O biodigestor é calculado em função do consumo de gás do conjunto motor-gerador, do número de horas de funcionamento da carga, da pressão desejada e da profundidade admissível do solo.

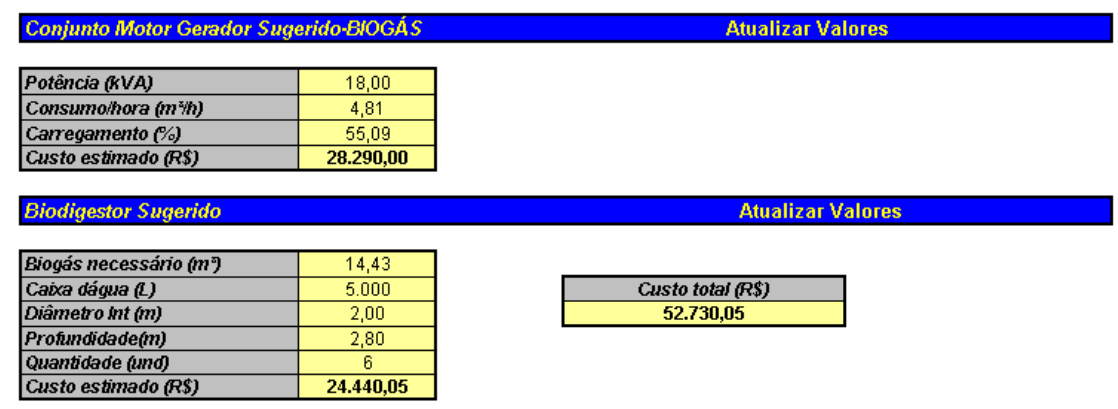

FIGURA 4. Tela para dimensionamento do conjunto motor-gerador e do biodigestor. Screen for generator set and biodigester designing.

No presente estudo, optou-se por utilizar como gasômetro caixas d'água em fibra de vidro, encontradas com facilidade comercialmente, em volumes de 5; 10 e $15 \mathrm{~m}^{3}$ (CARVALHO et al., 2004).

Visando à realização de análise atualizada, os valores de cada item da planilha podem ser atualizados por meio do hiperlink Atualizar Valores, localizado no canto superior direito da Figura 4.

Ainda em relação ao uso de biogás para o acionamento do conjunto motor-gerador, o programa realiza análise da biomassa disponível informada pelo usuário. Essa análise é feita a partir do valor do gerador dimensionado pela planilha e das quantidades informadas na tela de entrada de dados. Os resultados retornados são:

- Biogás disponível: é a quantidade de biogás que pode ser produzido a partir da quantidade de animais e/ou matéria orgânica informada na entrada de dados.

- Déficit de biogás: é a quantidade de gás necessária para atender plenamente à demanda do gerador; em outras palavras, a diferença entre a demanda do gerador e a quantidade de biogás produzida, quando a demanda é maior do que a produção.

- Tempo de funcionamento: é a quantidade de horas diárias de funcionamento em função do biogás disponível. Limita-se à quantidade de horas de funcionamento da carga informada pelo usuário.

- Excedente biogás: é fornecido quando a produção de biogás é maior que a demanda do gerador. É a diferença entre o biogás produzido e o utilizado para atender ao consumo do conjunto motor-gerador.

- Excedente energia estimada: informa a quantidade de energia $\left(\mathrm{kWh} \mathrm{dia}^{-1}\right)$ que pode ser gerada a partir do biogás excedente.

- Horas de funcionamento por dia: informa a quantidade de horas que o gerador pode funcionar a mais, em função do biogás excedente. 
- Opções de acréscimo: sugere a quantidade de animais e/ou de matéria orgânica necessária para atender à demanda em caso de déficit de biogás.

\section{b) Diesel}

Para o dimensionamento do grupo motor-gerador diesel, são utilizados os mesmos princípios do dimensionamento do motor-gerador a biogás.

A importância desse tipo de gerador, ainda que utilize a queima de combustível fóssil, é sua larga difusão no meio rural e, sobretudo, a possibilidade de substituição desse combustível por biodiesel.

\section{Passo 4 - Solar fotovoltaico}

Nesse bloco, são dimensionados os arranjos fotovoltaicos de forma individualizada, ou seja, de acordo com a demanda de cada consumidor. Foi utilizado, para os cálculos, o método desenvolvido pelo Grupo de Trabalho de Energia Solar (CRESESB, 1999).

\section{Passo 5 - Energia eólica}

Nesse passo, são dimensionados, similarmente ao anterior, os sistemas eólicos; como recurso adicional, há a interação com outro programa computacional chamado ventos.xls (SABINO JÚNIOR, 2003).

Os aerogeradores disponíveis na biblioteca do programa são de pequeno porte (na faixa de alguns kW), com especial atenção aos da empresa Enersud, fabricados no Brasil.

Ao pressionar o hyperlink Abrir o programa Ventos.xls, o usuário tem acesso à tela inicial da planilha que permite, a partir da medição de velocidade de vento de uma localidade, calcular a energia elétrica gerada pelo aerogerador escolhido pelo usuário em sua biblioteca.

São oferecidas três opções de entrada de dados: um ponto de medição, dois pontos de medição ou dados processados.

Para a opção um ponto de medição, o usuário deve informar, além dos dados de velocidade do vento, a altura em que foi tomada a medição e qual a rugosidade do terreno.

Para a opção dois pontos de medição, o usuário informa somente os dados de velocidade do vento e as respectivas alturas de medição, cabendo à planilha calcular a rugosidade junto com os demais parâmetros.

Na opção dados processados, o usuário deve informar a velocidade média dos ventos, a altura de medição, a rugosidade do local e o fator de forma.

Para quaisquer modalidades de medição, o usuário deve selecionar, em campo apropriado, o modelo do aerogerador a ser utilizado.

O dimensionamento dos sistemas eólicos segue o mesmo princípio adotado para a geração fotovoltaica do ponto de vista da carga, ou seja, utiliza-se o mesmo arranjo de baterias, controladores de carga e inversores.

Continuando no uso do programa, o usuário é conduzido para a etapa de análise financeira.

\section{Passo 6 - Análise financeira}

Nesse momento, são calculados os parâmetros financeiros de cada modalidade de fornecimento de energia elétrica e, por fim, são apresentados, no último bloco, gráficos comparativos dos resultados obtidos.

Para a análise financeira, é utilizado o método do fator de recuperação de capital, dado por (HESS et al., 1986; REIS et al., 2006): 


$$
R=P\left[\frac{i(1+i)^{n}}{(1+i)^{n}-1}\right]
$$

em que,

$\mathrm{P}$ - investimento total, $\mathrm{R} \$$;

$\mathrm{R}$ - retirada anual para que se recupere o investimento, $\mathrm{R} \$$

i - taxa mínima de atratividade, e

$\mathrm{n}$ - vida útil do projeto, anos.

Quanto menor o valor de R, melhor é o investimento.

O programa GDER adota que todas as alternativas de fornecimento de energia elétrica possuem vida útil de 20 anos, e as quantidades de energia fornecidas ou consumidas são absolutamente iguais.

Para a análise do Benefício/Custo (B/C), todos os valores envolvidos são atualizados segundo seu Valor Presente Líquido (VPL) em Reais (R\$) e, em seguida, relacionados conforme eqs.(2) e (3):

$$
\begin{aligned}
& V P L=\sum_{j=1}^{n} \frac{\text { valor }_{j}}{(1+i)^{j}} \\
& B / C=\frac{\sum \text { VPL }(\text { energia } ; \mathrm{i} ; \mathrm{n})}{\sum \text { VPL }(\text { custos } ; \mathrm{i} \mathrm{n})}
\end{aligned}
$$

Quanto maior for a relação Benefício/Custo, mais atraente é o investimento (B/C >1).

Para a análise do preço do custo do $\mathrm{kWh}$ produzido, é adotada a relação do custo anualizado obtido pela eq.(1) e a quantidade de energia elétrica em $\mathrm{kWh}$ gerada ao longo de um ano ( $\left.\mathrm{E}_{\mathrm{ano}}\right)$, conforme eq.(4):

$$
\mathrm{R} \$ / \mathrm{kWh}=\frac{\mathrm{R}}{\mathrm{E}_{\text {ano }}}
$$

Quanto menor for o custo do $\mathrm{kWh}$, mais atraente é o investimento.

\section{Passos 7 - Gráficos}

A tela análise financeira possui o hyperlink Ver Gráficos que apresenta, em outra tela, gráficos relativos às análises realizadas.

\section{Validação do GDER por meio de estudo de caso}

Para a avaliação da validade do programa GDER, utilizam-se como estudo de caso duas comunidades rurais. Ambas estão situadas no semiárido nordestino e possuem renda familiar média inferior a um salário mínimo, cuja atividade econômica se limita à agricultura de subsistência.

A primeira comunidade estudada está localizada na zona rural do município de Petrolina - PE, às margens da BR235, na altura do $\mathrm{km} \mathrm{12,} \mathrm{a} \mathrm{aproximadamente} 18 \mathrm{~km}$ da sede municipal. Trata-se de um assentamento feito pelo Instituto Nacional de Colonização e Reforma Agrária (INCRA), no ano de 2002, e que foi atendido, no final do ano de 2005, pelo programa Luz Para Todos (LPT).

A segunda é uma comunidade rural conhecida como Povoado de Almas, localizada no município de Casa Nova, no Estado da Bahia, distante $25 \mathrm{~km}$ da sede municipal e a $76 \mathrm{~km}$ da sede do município de Petrolina - PE. A rede elétrica convencional mais próxima encontra-se à distância de $12 \mathrm{~km}$ do povoado, que conta com 28 domicílios, dos quais 25 foram atendidos pelo Programa Luz Para Todos no segundo semestre de 2006.

Os principais parâmetros de entrada para os dois casos são apresentados na Tabela 1. 
TABELA 1. Principais parâmetros de entrada para o estudo de validação do programa GDER. Main entry parameters for validation studies of the GDER program.

\begin{tabular}{lcc}
\hline \multicolumn{1}{c}{ Dados de Entrada } & Assentamento $1^{-}$de Maio - PE & Povoado de Almas - BA \\
\hline Taxa de crescimento populacional para o local & $1 \%$ & $1 \%$ \\
Fator diversidade & 0,7 & 0,7 \\
Horas de funcionamento diário & 3,0 & 3,0 \\
Potência instalada por unidade $(\mathrm{W})$ & 500 & 500 \\
Quantidade de unidades consumidoras & 18 & 25 \\
Disponibilidade de matéria orgânica & 68 caprinos & Não há \\
Profundidade admissível do solo (m) & 5,0 & 5,0 \\
Pressão de gás desejada (m.c.a.) & 0,15 & 0,15 \\
Velocidade do vento (m s $\left.{ }^{-1}\right)$ & 6,0 & 6,0 \\
Taxa de retorno & $10 \%$ & $10 \%$ \\
Preço do kWh para o local $(\mathrm{R} \$)$ & 0,08 & 0,08 \\
Valor médio de rede elétrica $\left(\mathrm{R} \$ \mathrm{~km}^{-1}\right)$ & $26.0000,00$ & $26.0000,00$ \\
Distância da rede elétrica $(\mathrm{km})$ & 2,0 & 12,0 \\
Salário mínimo vigente $(\mathrm{R} \$)$ & 350,00 & 350,00 \\
Preço estimado do biofertilizante $\left(\mathrm{R} \$ \mathrm{~m}^{-3}\right)$ & 1,00 & 1,00 \\
Vida útil das baterias (anos) & 5 & 5 \\
\hline
\end{tabular}

\section{DISCUSSÃO DOS RESULTADOS}

Para a comunidade "Assentamento $1^{\circ}$ de Maio", o programa GDER calculou os valores contidos na Tabela 2, que são disponibilizados para o usuário em forma de gráficos, conforme Figuras 5 e 6.

TABELA 2. Resultados da análise financeira da comunidade "Assentamento $1^{\circ}$ de Maio". Results of the financial analysis of "Assentamento $1^{0}$ de Maio" village.

\begin{tabular}{cccccc}
\hline Dados de Entrada & Biogás & Diesel & Solar & Eólica & \multicolumn{1}{c}{ Rede } \\
\hline Relação Benefício/Custo (B/C) & 1,641 & 1,606 & 3,856 & 10,893 & 1,110 \\
Custo em Reais do kw (R\$ kWh $^{-1}$ ) & 0,088 & 0,049 & 0,020 & 0,007 & \multicolumn{1}{c}{0,071} \\
Custo inicial de instalação (R\$) & $52.730,05$ & $15.116,00$ & $208.650,00$ & $593.316,00$ & $52.000,00$ \\
Custo anualizado (R\$) & $11.043,49$ & $10.362,03$ & $24.881,41$ & $70.282,85$ & $7.164,41$ \\
\hline
\end{tabular}

De acordo com a Figura 5, o fornecimento de energia elétrica por meio da extensão da rede convencional apresenta o menor custo de $\mathrm{kWh}$, embora a relação Benefício/Custo não seja a maior.

Como segunda opção, em função do custo do kWh produzido, tem-se a geração por conjunto motor-gerador a diesel com diferença de 40\%, comparada à primeira opção, e uma relação Benefício/Custo relativamente baixa.

A opção de fornecimento de eletricidade por meio de conjunto motor-gerador a biogás apresentou custo do $\mathrm{kWh}$ próximo ao motor-gerador a diesel, e a melhor relação Benefício/Custo entre as alternativas. Tal condição deve-se ao fato de o conjunto gerar seu próprio combustível e da possibilidade de comercialização do biofertilizante.

No entanto, o programa emitiu, logo abaixo do gráfico da Figura 5, mensagem de alerta de que há restrições quanto à produção de biogás (déficit de 9,33 $\mathrm{m}^{3}$ ), posto que a comunidade em questão não dispõe de matéria orgânica suficiente para atender à demanda do conjunto motorgerador a biogás; dessa forma, é necessário que a biomassa seja complementada de forma a suprir a demanda por biogás satisfatoriamente. Essa condição, por exemplo, pode ser atendida por meio de iniciativas que incentivem a expansão da criação de animais e/ou o aproveitamento de restos de lavouras.

Vale ressaltar que, ainda que não seja utilizado para produção de energia elétrica, o biogás pode ser aproveitado para cocção em substituição à lenha, tanto nas residências como em alguma atividade cooperada que agregue trabalho e renda na comunidade, contribuindo, portanto, para 
melhor qualidade de vida dos usuários, bem como auxiliando no combate à desertificação (BORGES NETO et al., 2006).

As alternativas solar FV e eólica são as menos atraentes, principalmente em função dos custos dos equipamentos envolvidos e, no caso eólico, do regime de ventos para a localidade, fato refletido também na relação Benefício/Custo (0,020 e 0,007, respectivamente).

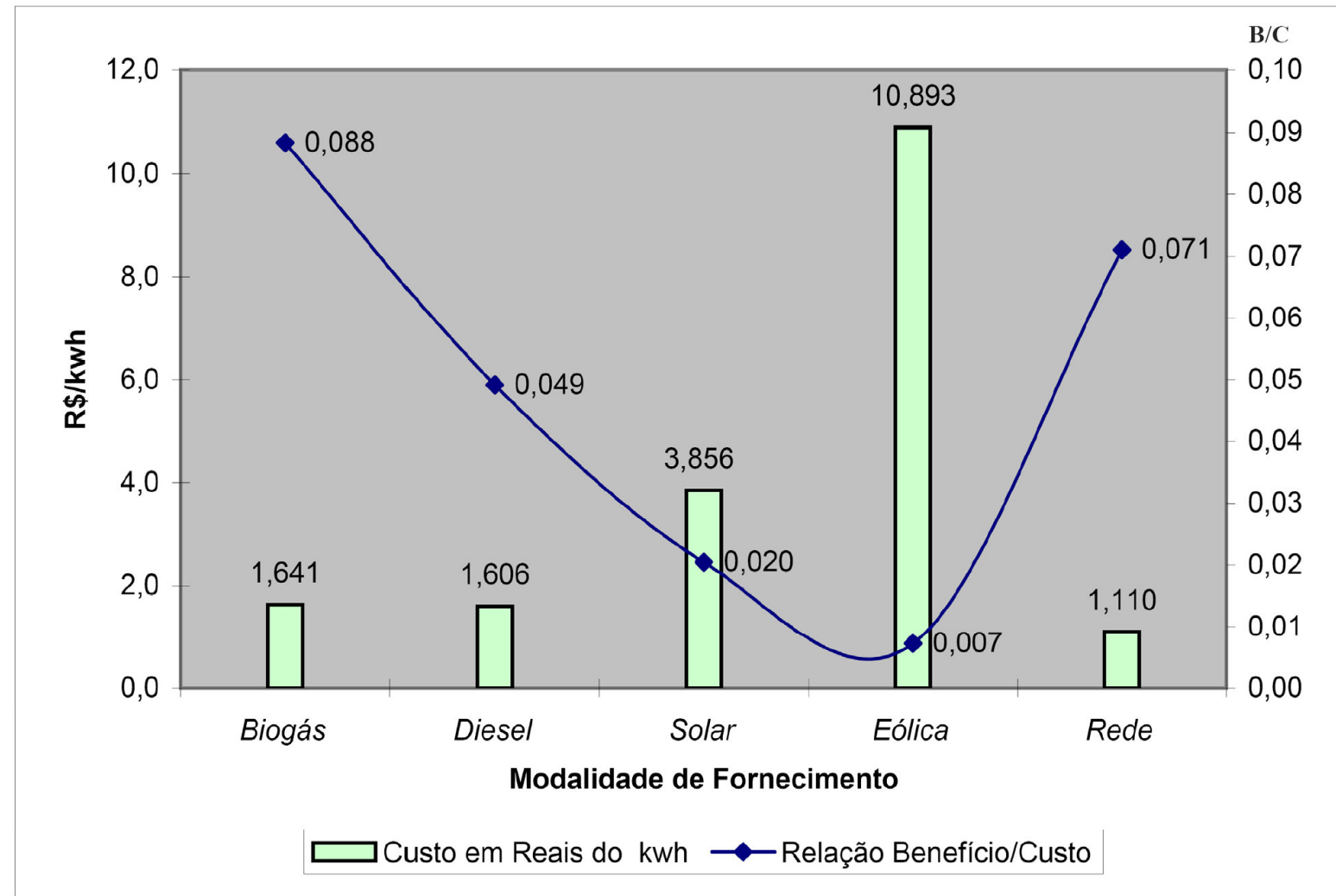

Obs: há restrições quanto à diponibilidade de biomassa! Déficit de: $-9,33 \quad \mathrm{~m}^{3}$

FIGURA 5. Valor do custo do kWh produzido e da relação Benefício/Custo da comunidade "Assentamento $1^{\circ}$ de Maio", em Petrolina - PE. Chart of $\mathbf{k W h}$ produced cost and the rate Benefit/Cost of "Assentamento 1" de Maio" village in Petrolina - PE.

No gráfico da Figura 6, o menor investimento inicial é do conjunto motor-gerador a diesel. Em análise preliminar, o consumidor, diante de tal condição, certamente seria impelido a optar por tal modalidade de geração de energia elétrica. Porém, essa alternativa apresenta custo anualizado superior à rede elétrica convencional, consequência da necessidade de aquisição de óleo diesel para abastecer o conjunto. Logo, apesar de a extensão da rede necessitar de investimento inicial maior, seus custos, ao longo dos anos, são menores.

O LPT, por meio da Companhia Energética de Pernambuco (CELPE), executou a obra de extensão da rede elétrica convencional trifásica para a comunidade " 1 o de Maio", no mês de dezembro de 2005 , ao custo final de $\mathrm{R} \$ 42.824,32$.

A modalidade de geração por motor-gerador a biogás exige aporte inicial de recursos um pouco superior ao da extensão da rede elétrica convencional. Porém, o custo anualizado é significativamente maior do que seria se houvesse comércio garantido para o biofertilizante produzido pela comunidade.

Os resultados para a geração solar FV e eólica também explicam os valores demonstrados na Figura 5, pois ambas as tecnologias requerem investimento inicial elevado, que remete a um custo 
anualizado igualmente alto, caracterizando, portanto, a inviabilidade dessas alternativas de fornecimento de eletricidade.

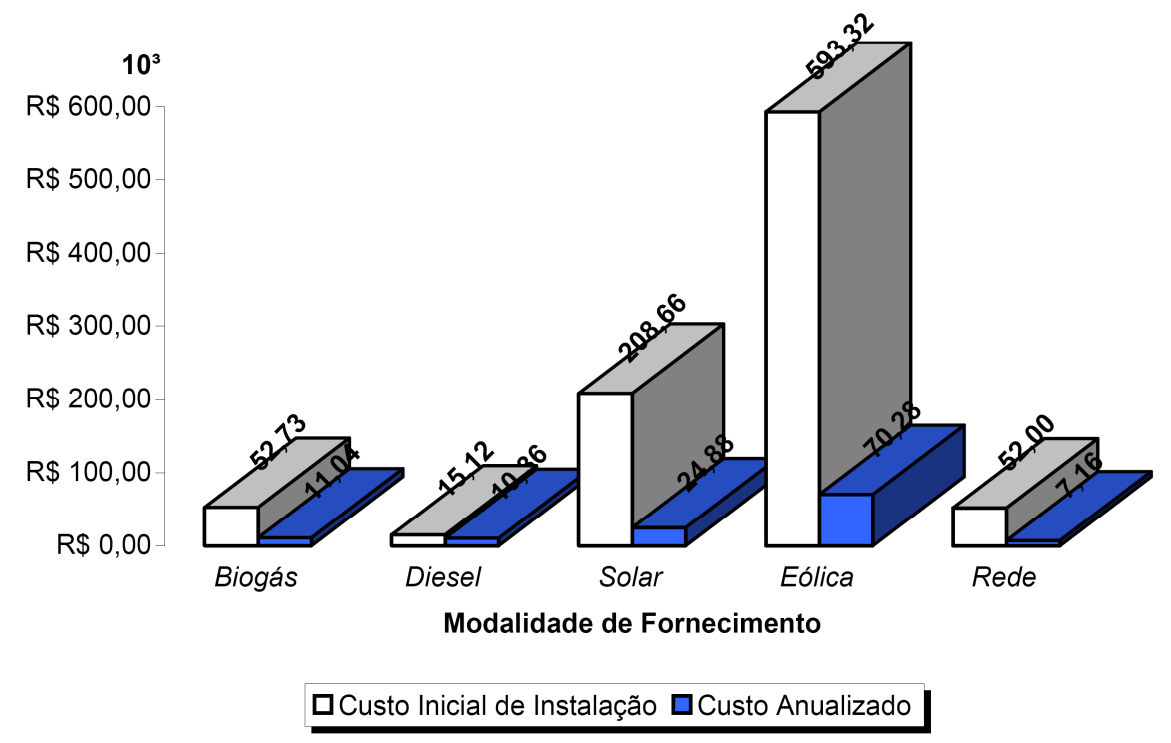

FIGURA 6. Valor do custo de instalação inicial e do valor do custo anual de recuperação de capital da comunidade "Assentamento $1^{\mathrm{o}}$ de Maio", em Petrolina - PE. Chart of initial installation cost and the value of annual recovering capital of "Assentamento $1^{\mathrm{o}}$ de Maio" village in Petrolina - PE.

Para o "Povoado de Almas", o programa GDER retornou os valores exibidos na Tabela 3 e representados nos gráficos das Figuras 7 e 8.

Nessa comunidade, não foi registrada nenhuma quantidade significativa de animais ou outro tipo de fonte de matéria orgânica que justificasse a produção de energia elétrica utilizando biogás; todavia, o programa calculou o conjunto motor-gerador a biogás, os biodigestores e o volume de biogás de que o sistema necessitaria, caso houvesse matéria orgânica disponível $\left(14,43 \mathrm{~m}^{3}\right)$. Apesar desses dimensionamentos, essa modalidade de fornecimento não é levada em consideração para a análise financeira, explicando os resultados de valor do $\mathrm{kWh}$ e da relação Custo/Benefício iguais a zero.

Dentre as alternativas analisadas, o motor-gerador a diesel ofereceu o menor custo de $\mathrm{kWh}$ produzido, assim como a melhor relação Benefício/Custo que, do ponto de vista estritamente financeiro, é a melhor opção.

A segunda melhor alternativa foi o fornecimento de eletricidade por meio da tecnologia FV, que apresentou custo por $\mathrm{kWh}$ gerado inferior ao calculado para a extensão da rede convencional e com a relação Benefício/Custo muito próximo, porém melhor ao da extensão da rede convencional.

A extensão da rede só é atraente ao ser comparada à alternativa da geração eólica, cujo preço do $\mathrm{kWh}$ produzido é de $\mathrm{R} \$ 10.882,00$ e o Custo/Benefício de 0,007 , justificado pelo baixo regime de ventos e elevados preços dos equipamentos.

TABELA 3. Resultados da análise financeira do "Assentamento Povoado de Almas. Results of the financial analysis of "Assentamento Povoado de Almas" village.

\begin{tabular}{cccccc}
\hline Dados de Entrada & Biogás & Diesel & Solar & Eólica & Rede \\
\hline Relação Benefício/Custo (B/C) & 0 & 0,68 & 0,021 & 0,007 & 0,016 \\
Custo em Reais do kW (R $\left.\$ \mathrm{kWh}^{-1}\right)$ & 0 & 1,16 & 3,85 & 10,88 & \multicolumn{1}{c}{4,80} \\
Custo inicial de instalação $(\mathrm{R} \$)$ & $52.730,05$ & $15.116,00$ & $289.800,00$ & $824.050,00$ & $312.000,00$ \\
Custo anualizado $(\mathrm{R} \$)$ & - & $10.362,03$ & $34.458,84$ & $97.516,39$ & $42.984,00$ \\
\hline
\end{tabular}




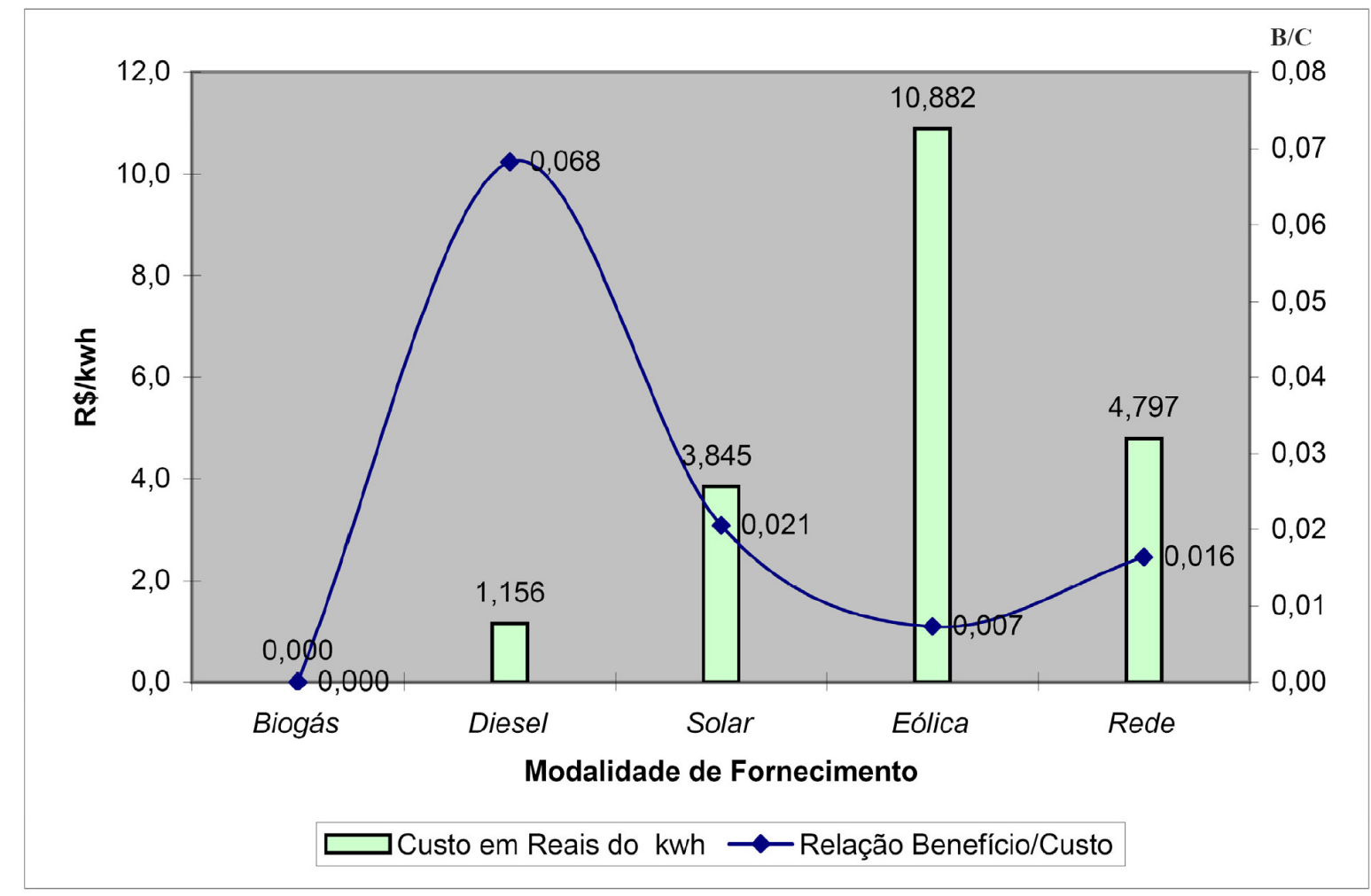

Obs: não há biomassa para produção de biogás! Déficit de: $-14,43 m^{3}$

FIGURA 7. Valor do custo do kWh produzido e da relação Benefício/Custo para o "Povoado de Almas", em Casa Nova - BA. Chart of $\mathbf{k W h}$ produced cost and the rate Benefit/Cost of "Povoado de Almas" village in Casa Nova - BA.

Na Figura 8, a geração por conjunto motor-gerador diesel apresentou-se como a melhor alternativa, tanto pelo investimento inicial como pelo custo anualizado.

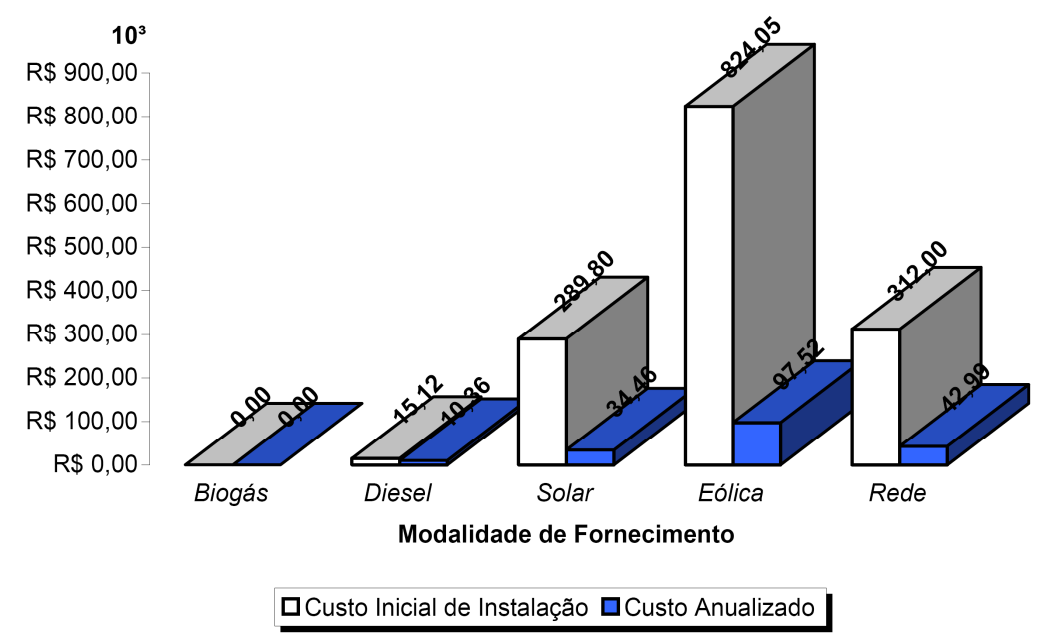

FIGURA 8. Valor do custo de instalação inicial e valor do custo anual de recuperação de capital para o "Assentamento Povoado de Almas", em Casa Nova - BA. Chart of initial installation cost and the value of annual recovering capital of "Assentamento Povoado de Almas" village in Casa Nova - BA. 
O investimento inicial para a tecnologia FV foi próximo, contudo inferior ao estimado para a rede convencional. Por sua vez, o custo anualizado para a alternativa solar FV foi significativamente menor que o da rede convencional de energia.

O investimento inicial e o custo anualizado para o fornecimento de energia elétrica por meio de sistemas eólicos confirmam a inviabilidade para a região.

O LPT, por meio da Companhia Energética da Bahia (COELBA), estimou o custo da extensão da rede convencional para atender o "Povoado de Almas" em R \$ 460.000,00. Decidiu-se atender o povoado por meio de sistemas fotovoltaicos que, ao final da execução, apresentaram custo final de R \$ 118.158,00. A diferença entre os custos reais para fornecimento por FV e o calculado pelo programa (R \$ 289.800,00) deveu-se ao arranjo utilizado pelo LPT ter capacidade de geração e armazenamento menor que o dimensionado como ideal pelo GDER.

\section{CONCLUSÕES}

O programa computacional GDER superou as principais limitações identificadas em produtos similares disponíveis no mercado mundial e descritos na literatura científica. Como resultados favoráveis podem ser listados:

- Baixo custo: foi desenvolvido em Excel® em vista a boa difusão dessa plataforma entre os usuários de computadores.

- Facilidade de operação: permite ao usuário que, com o mínimo de informações, obtenha um prognóstico de viabilidade técnica e econômica, comparando à extensão de uma rede convencional de distribuição de energia elétrica com as possibilidades de geração descentralizada.

- Estímulo à adoção da geração descentralizada: por meio de tecnologias convencionais e de energias renováveis como solar fotovoltaica, eólica, biogás e diesel.

- Adequação à realidade brasileira: oferecendo aos usuários no Brasil programa em português, com a inovação do uso de biogás produzido por biodigestores na própria localidade. Essa opção não está disponível em programas similares.

- Orientações que extrapolam o uso da energia elétrica: uma vez que é possível avaliar potenciais de biogás para fins de cocção ou outros processos térmicos.

Os valores finais a maior estimados pelo programa GDER comparados aos valores reais de execução das obras, nos dois casos reais (21 e 140\%, respectivamente), são explicados em função de que o programa trabalha com valores médios de entrada e, especificamente, no segundo caso, os arranjos fotovoltaicos utilizados pela concessionária apresentam capacidade de fornecimento inferior ao recomendado pela literatura científica. Tal condição não invalida a aplicação do programa que, apesar das diferenças observadas, indicou corretamente as melhores opções de fornecimento para as comunidades avaliadas.

\section{REFERÊNCIAS}

BORGES NETO, M.R.; LOPES L.C.N.; LIMA A.C.; RIBEIRO J.T.F. Demanda de energia para cocção no meio rural. In: CONGRESSO BRASILEIRO DE ENGENHARIA AGRÍCOLA, 35., 2006, João Pessoa. Anais... Jaboticabal: Associação Brasileira de Engenharia Agrícola, 2006. 1 CDROM.

CARVALHO, P.C.M.; CRAVEIRO, P.M.A. Introdução ao planejamento energético. Fortaleza: IEPRO/SEINFRA, 2006. 94 p.

CARVALHO, P.C.M.; SILVEIRA NETO, J.W.; CANAFÍSTULA, F.J.F.; DINIZ, M.N.M.

Biodigestor para validação de sistema produtivo autossustentável no semiárido. In: ENCONTRO DE ENERGIA NO MEIO RURAL, 5., 2004, Campinas. Anais... Campinas: NIPE/UNICAMP, 2004. 1 CD-ROM. 
CRESESB. CENTRO DE REFERÊNCIA PARA ENERGIA SOLAR E EÓLICA SÉRGIO DE SALVO BRITO. Manual de engenharia para sistemas fotovoltaicos. Rio de Janeiro, 1999. 204 p.

DIAS, M.V.; BORTONI, E.C.; HADDAD, J. Geração distribuída no Brasil: oportunidades e barreiras. In: CONGRESSO BRASILEIRO DE PLANEJAMENTO ENERGÉTICO, 5., 2006, Brasília. Anais... Brasília: Sociedade Brasileira de Planejamento Energético, 2006. 1 CD-ROM.

HESS, G.; MARQUES, J.L.; PAES, L.C.R.; PUCCINI, A. Engenharia Econômica. São Paulo: DIFEL, 1986. $165 \mathrm{p}$.

MARINI, J.A.; ROSSI, L.A. Sistematização do dimensionamento técnico e econômico de sistemas fotovoltaicos isolados por meio de programa computacional. Engenharia Agrícola, Jaboticabal, v.25, n.1, p.67-75, 2005.

NASCIMENTO, M.V.G.; VIEIRA, L.S.; SOARES, G.F. Análise econômica comparativa entre opções para suprimento energético ininterrupto de pequenas comunidades. In: SEMINÁRIO NACIONAL DE PRODUÇÃO E TRANSMISSÃO DE ENERGIA ELÉTRICA, 17., 2003, Uberlândia. Anais... Uberlândia: Comitê Nacional Brasileiro de Produção e Transmissão de Energia Elétrica, 2003. 1 CD-ROM.

NASCIMENTO, M.V.G.; MELLO, J.C.O.; PIZETA, E.G.; CASTRO, A.L.; SPALDING, E.C.; BIANCO, A. A participação crescente dos encargos setoriais no custo de energia brasileiro In: SEMINÁRIO NACIONAL DE PRODUÇÃO E TRANSMISSÃO DE ENERGIA ELÉTRICA, 18., 2005, Curitiba. Anais...Curitiba: Comitê Nacional Brasileiro de Produção e Transmissão de Energia Elétrica, 2005. 1 CD-ROM.

NOGUEIRA, C.E.; ZÜRN, H.H. Modelo otimizado para sistemas energéticos renováveis em ambientes rurais. Engenharia Agrícola, Jaboticabal, v.25, n.2, p.341-348, 2005.

QUASCHINING, V.; ZEHNER, M. Simulate it in English. Sun \& Wind Energy, Bielefeld, v.1, n.1, p.50-56, 2004.

REIS, M.M.; OLIVEIRA JÚNIOR, D.S.; CARVALHO, P.C.M. Estudo da viabilidade econômica de geradores eólicos de pequeno porte no modo autônomo. In: SIMPÓSIO BRASILEIRO DE SISTEMAS ELÉTRICOS, 1., 2006, Campina Grande. Anais... Campina Grande: Universidade Federal de Campina Grande, 2006. 1 CD-ROM.

SABINO JÚNIOR, F.R. Ferramenta computacional para o cálculo da produção de eletricidade de geradores eólicos de pequeno porte. 2003. 94 f. Dissertação (Mestrado em Engenharia Elétrica) Universidade Federal do Ceará, Fortaleza, 2003.

WEITZEL, L.; ROVERE, E.L.; CUNHA R. As demandas do novo modelo institucional do setor elétrico brasileiro. In: CONGRESSO BRASILEIRO DE PLANEJAMENTO ENERGÉTICO, 5., 2006, Brasília. Anais... Brasília: Sociedade Brasileira de Planejamento Energético, 2006. 1 CDROM. 